\title{
Pcsk6 mutant mice exhibit progressive loss of ovarian function, altered gene expression, and formation of ovarian pathology
}

\author{
Michelle L Mujoomdar ${ }^{1}$, Laura M Hogan ${ }^{1}$, Albert F Parlow ${ }^{2}$ and Mark W Nachtigal ${ }^{1,3}$ \\ ${ }^{1}$ Department of Pharmacology, Faculty of Medicine, Dalhousie University, Halifax, Nova Scotia B3H 1X5, Canada, \\ ${ }^{2}$ National Hormone and Peptide Program, Harbor-UCLA Medical Center, Torrance, California 90502, USA and \\ ${ }^{3}$ Department of Medicine, Faculty of Medicine, Dalhousie University, Halifax, Nova Scotia B3H 1X5, Canada
}

Correspondence should be addressed to $M W$ Nachtigal who is now at Department of Biochemistry and Medical Genetics, Faculty of Medicine, University of Manitoba, 309B BMSB, 745 Bannatyne Avenue, Winnipeg, Manitoba, Canada;

Email: mark_nachtigal@umanitoba.ca

\begin{abstract}
Bioactivation of precursor proteins by members of the proprotein convertase (PC) family is essential for normal reproduction. The Pcsk6 gene is a member of the PC family that is expressed in numerous ovarian cell types including granulosa cells and oocytes. We hypothesized that loss of PCSK6 would produce adverse effects in the mouse ovary. Mice incapable of expressing PCSK6 (Pcsk6 ${ }^{\text {tm1 }}$ Rob) were obtained, and reproductive parameters (serum hormones, whelping interval, estrus cyclicity, and fertility) were compared to Pcsk6 $^{+/+}$mice. While Pcsk6 ${ }^{\text {tm1 Rob }}$ female mice are fertile, they manifest reduced reproductive capacity at an accelerated rate relative to Pcsk6 $^{+/+}$mice. Reproductive senescence is typically reached by 9 months of age and is correlated with loss of estrus cyclicity, elevated serum FSH levels, and gross alterations in ovarian morphology. A wide range of ovarian morphologies were identified encompassing mild, such as an apparent reduction in follicle number, to moderate - ovarian atrophy with a complete absence of follicles - to severe, manifesting as normal ovarian structures replaced by benign ovarian tumors, including tubulostromal adenomas. Targeted gene expression profiling highlighted changes in RNA expression of molecules involved in processes such as steroidogenesis, gonadotropin signaling, transcriptional regulation, autocrine/paracrine signaling, cholesterol handling, and proprotein bioactivation. These results show that PCSK6 activity plays a role in maintaining normal cellular and tissue homeostasis in the ovary.

Reproduction (2011) 141 343-355
\end{abstract}

\section{Introduction}

The subtilisin-like proprotein convertase (PC) family of serine endoproteases is one class of enzymes that facilitate proprotein cleavage into their bioactive mature forms (reviewed in Seidah \& Chretien (1999)). There is growing evidence that alterations in PC activity contribute to human pathologies including cancer, viral infections, and metabolic disorders (Taylor et al. 2003, Bassi et al. 2005, Maxwell \& Breslow 2005, Seidah et al. 2006, latan et al. 2009). Seven mammalian PCs cleave precursor proteins at basic amino acid residues with the motif $(\mathrm{K} / \mathrm{R})-(\mathrm{X})_{n^{-}}(\mathrm{K} / \mathrm{R})$ ( $\mathrm{K}=$ lysine, $\mathrm{R}=$ arginine, $\mathrm{X}=$ any amino acid): PCSK1-7. The PCs SKI-1/S1P and PCSK9 cleave substrates at non-basic residues. PC substrates encompass numerous protein precursors such as peptide hormones, growth and differentiation factors, receptors, proteases, and adhesion molecules (Seidah \& Chretien 1999, Seidah et al. 2006). Known substrates that participate in reproductive physiology include proGNRH, pro-IGF1, IGF1 pro-receptor, pro-fertilins, pro-pituitary adenylate cyclase-activating polypeptide, and members of the transforming growth factor $\beta$ (TGFB) superfamily (Seidah \& Chretien 1999).

PCSK6 exhibits a broad pattern of expression including heart, brain, placenta, lung, liver, uterine endometrium, and ovary (Kiefer et al. 1991, Fu et al. 2003, Freyer et al. 2007, Diaz et al. 2008). PCSK6 is a secreted, heparinbinding protein that is tethered to the plasma membrane through binding with members of the tissue inhibitors of metalloproteinase family (Tsuji et al. 2003, Jin et al. 2005, Nour et al. 2005). While PCSK6 is capable of cleaving a variety of substrates in vitro, it has been difficult to assign specific substrate partners to individual proteases due to redundant proteolytic activities shared among related family members, e.g. PCSK3 (furin). The best evidence for bona fide targets of PCSK6 comes from a combination of in vivo and in vitro experiments. These substrates include nodal (Constam \& Robertson 2000, Beck et al. 2002), which is critical for body axis formation, and endothelial lipase (Gauster et al. 2005, Jin et al. 2005, Nour et al. 2005), a member of the triglyceride lipase family that regulates plasma lipoprotein concentrations (Ishida et al. 2003, Ma et al. 2003). 
In mice, PCSK6 protein is encoded by the Pcsk6 gene (Mbikay et al. 1995). Recent work from Diaz et al. (2008) has shown that expression of Pcsk6 RNA in the mouse ovary corresponds primarily to granulosa cells of small to medium preantral follicles. St Germain et al. (2005) have shown that Pcsk6 was expressed by oocytes. Diaz et al. have further shown that Pcsk6 mRNA expression was suppressed during the preantral to antral transition through oocyte-derived factors. These investigators speculated that PCSK6 might have an important function in the proteolytic processing of ovarian substrates critical to maintain normal follicular biology. Although the dynamic change in PCSK6 expression suggests that an alteration in substrate processing or activity occurs during the preantral to antral transition, it is not definitively known whether PCSK6 activity is required for follicle maturation or any other aspects of ovarian function.

Based on the pattern of expression in the mouse ovary and the putative PCSK6 substrates that participate in reproductive physiology, we hypothesized that loss of PCSK6 expression would generate an ovarian phenotype. In particular, we would predict a defect in follicle biology that may be complemented by alterations in ovarian morphology. To investigate the relative contribution of Pcsk6 deletion to ovarian biology in an experimental model system, we obtained mice that were incapable of expressing PCSK6 (PCSk6 $\left.{ }^{t m 1 R o b}\right)$ from the laboratory of Dr Daniel Constam (Swiss Institute for Experimental Cancer Research; Constam \& Robertson 2000). Approximately $25 \%$ of Pcsk $6^{t m 1 R o b}$ mice exhibit left-right axis defects, severe craniofacial abnormalities, and embryonic lethality by embryonic day (e) 15.5 (Constam \& Robertson 2000). Approximately, for the $75 \%$ of mice that are viable, it is reported that these animals are capable of reproducing (Constam \& Robertson 2000), but no in-depth analyses of their reproductive biology have been published. With the availability of viable Pcsk6 tmiRob mice, we can determine whether the loss of PCSK6 has an impact on ovarian biology. This study examined ovarian morphology, ovulation, fertility, hormone production, and gene expression in Pcskb ${ }^{\text {tm1Rob }}$ mice. We determined that loss of Pcsk6 expression results in premature reproductive senescence at $\sim 9$ months $(\mathrm{mo})$ of age in addition to the development of ovarian morphological pathologies ranging from an apparent reduction in follicle number to tumor formation.

\section{Results \\ Pcsk6 ${ }^{\text {tm1 Rob }}$ female mice have a reduced reproductive capacity}

To determine the effect that PCSK6 expression may have on female reproductive capacity, $P \operatorname{csk} 6^{+/+}$and Pcsk6 $6^{\text {tm1Rob }}$ female mice were mated with $P$ csk $6^{+/+}$ male mice. Pairs capable of producing a minimum of three litters over the study period were included in these analyses (one $P c s k 6^{+/+}$pair and three ccsk6 $^{+/+}$male $\times P c s k 6^{t m 1 R o b}$ female pairs were excluded from these analyses). The comparison of the mean number of pups born per litter was not statistically significant; 6.6 for $P_{c s k 6^{+/+}}$pairs (8 pairs, 44 litters) and 7.5 for $P$ csk6 $6^{+/+}$ male $\times P c s k G^{\text {tmiRob }}$ female pairs (9 pairs, 49 litters; Table 1). Also, while the total number of litters born was not significantly different between the groups, the $P C s k 6^{t m 1 R o b}$ mice produced the majority of their litters up to 6 mo of age, with fewer litters born between 6 and 9 mo. By contrast, the number of litters born to Pcsk6 $6^{+/+}$ animals was evenly distributed throughout the breeding period. We observed that for mice used to maintain our breeding colonies, $\sim 25 \%$ of $P_{c s k 6}{ }^{+/+}$male $\times P_{C s k 6^{t m 1 R o b}}$ female matings (5 of 18 pairings) never produced a single litter, whereas only 1 of 21 matings of Pcsk6 ${ }^{+/+}$pairs did not produce offspring. Female PCsk6 ${ }^{\operatorname{tm} 1 R o b}$ mice showed a significantly increased whelping interval (32.4 \pm 3.1 days) compared with Pcsk6 ${ }^{+/+}$mice $(23.5 \pm 0.6$ days; Table $1, P<0.05)$. Furthermore, the median age of last litter for Pcsk $6^{\text {tm1Rob }}$ female mice was 2 mo earlier than that of $P c s k 6^{+/+}$ mice ( $8 \mathrm{vs} 10 \mathrm{mo}$ ). While not statistically different, a loss of 2 months of breeding capacity is biologically important and likely reflective of aberrant ovarian biology in these mice. The percentage of mice exhibiting regular estrous cyclicity was also compared (Table 2). As early as $7 \mathrm{mo}$, the proportion of Pcsk6 ${ }^{\text {tmiRob }}$ mice cycling regularly had decreased to $58 \%$, and by $9-10$ mo, this proportion had dropped to $16 \%$ and remained

Table 1 Number of litters, average litter size, and whelping interval for wild-type $(+/+)$ and $P_{C s k} 6^{\mathrm{tm} 1 \mathrm{Rob}}(-/-)$ mice.

\begin{tabular}{lccc}
\hline $\begin{array}{c}\text { Genotype } \\
\text { female } \times \text { male }\end{array}$ & $\begin{array}{c}\text { Number of } \\
\text { litters }^{\mathrm{a}}\end{array}$ & $\begin{array}{c}\text { Average } \\
\text { litter size }^{\mathrm{a}}\end{array}$ & $\begin{array}{c}\text { Average } \\
\text { whelping } \\
\text { interval (days) }\end{array}$ \\
\hline$+/+\times+/+$ & & & \\
$259 \times 244$ & 7 & 4.8 & 24 \\
$264 \times 275$ & 5 & 8.8 & 22 \\
$265 \times 276$ & 9 & 3.6 & 21.5 \\
$287 \times 288$ & 7 & 8.3 & 26 \\
$289 \times 290$ & 9 & 6.4 & 22.9 \\
$322 \times 324$ & 2 & 7.5 & 26 \\
$1367 \times 1368$ & 3 & 7.0 & 23.5 \\
$1369 \times 1370$ & 2 & 6.5 & 22 \\
& Total $=44$ & Mean $=6.6$ & Mean $=23.5$ \\
$-/-\times+1+$ & 7 & & \\
$123 \times 75$ & 7 & 9.0 & 37.8 \\
$190 \times 243$ & 7 & 11.0 & 32.5 \\
$268 \times 242$ & 7 & 8.4 & 29.8 \\
$308 \times 247$ & 6 & 8.6 & 28.8 \\
$317 \times 245$ & 2 & 7.0 & 25.4 \\
$318 \times 246$ & 3 & 2.5 & 46 \\
$402 \times 378$ & 8 & 6.7 & 21 \\
$403 \times 320$ & 2 & 7.7 & 23.6 \\
$419 \times 415$ & Total $=49$ & Mean $=7.5$ & 47 \\
& & & Mean $=32.4$ \\
\hline
\end{tabular}

${ }^{a}$ No statistically significant differences between $+/+X+/+$ and $-/-x+/+$ pairings. ${ }^{b} W h e l p i n g$ interval is significantly different between $+/+X+/+$ and $-/-X+/+$ pairings $(P<0.05)$. 
Table 2 Examination of estrous cyclicity in virgin female mice stratified by age and genotype.

\begin{tabular}{lcc}
\hline & \multicolumn{2}{c}{ Incidence of regular estrus cyclicity $(\%)$} \\
\cline { 2 - 3 } & \multicolumn{1}{c}{$P_{\text {Csk6 }}{ }^{+/+}$} & $P_{C s k 6}^{\text {tm1Rob }}$ \\
\hline Age (months) & $100(28)$ & $95(20)$ \\
$4-6$ & $82(17)$ & $58(29)$ \\
$7-8$ & $95(21)$ & $16(24)$ \\
$9-10$ & $63(19)$ & $25(31)$ \\
$11-13$ & \\
\hline
\end{tabular}

The number in parentheses indicates the number of animals examined for each condition.

low thereafter. Abnormal estrous cycles typically manifested as complete acyclicity. By contrast, the majority of $P$ csk6 $6^{+/+}$mice cycled regularly until 13 mo.

\section{The ovulatory capacity of Pcsk6 ${ }^{\text {tmob }}$ mice is decreased in response to exogenous hormonal stimulation}

Superovulation in response to exogenous gonadotropins was tested in mice at $30 \mathrm{~d}$ and $3 \mathrm{mo}$. At $30 \mathrm{~d}$, there was no statistically significant difference in the number of oocytes released by $P_{C s k 6}{ }^{+/+}(40.8 \pm 5.1)$ or Pcsk6 ${ }^{\text {tmlRob }}(51.8 \pm 5.4)$ mice. By 3 mo, Pcsk6 ${ }^{\text {tm1Rob }}$ mice showed a significantly reduced ovulatory response $(24.0 \pm 3.1)$ compared with $P c s k 6^{+/+}(35.5 \pm 3.8)$ animals $(P<0.05)$.

\section{Basal and eCG-stimulated serum steroids are equivalent between young female Pcskb ${ }^{+/+}$and Pcsk6 ${ }^{\text {tmikob }}$ mice}

Saline- and eCG-stimulated serum steroid levels (progesterone $\left(\mathrm{P}_{4}\right)$, testosterone, and estradiol $\left(\mathrm{E}_{2}\right)$ ) from cycling female mice ranging from 30 to 48 days were measured at 48 and $60 \mathrm{~h}$ post injection (Table 3). It should be noted that our initial studies examined serum steroid levels at $48 \mathrm{~h}$ in $P_{c s k} 6^{+/+}$and $P_{c s k} 6^{\text {tm1Rob }}$ mice, but we did not observe the expected change in $E_{2}$ production frequently reported in the literature. This is likely a factor inherent to our colony. As such, we extended our analyses to examine responses at $60 \mathrm{~h}$ post eCG injection. Increases in serum steroids were measured in both genotypes in response to eCG.

\section{Pcsk6 ${ }^{\text {tm1 Rob }}$ female mice exhibit altered gene expression in response to exogenous eCG}

Ovarian expression of selected target genes from female mice ranging from 30 to 48 days was examined by quantitative RT-PCR (QPCR) $60 \mathrm{~h}$ after saline or eCG injection (Fig. 1; Supplementary Figure 1, see section on supplementary data given at the end of this article, $48 \mathrm{~h}$ ). Similarities in the expected responses to eCG were observed for several known target genes; the relative basal level or magnitude of the response was significantly lower for Fshr and Cyp19a1 in PCsk6 $6^{\text {tm1Rob }}$ mice respectively.

RNA levels for the PCSK6 substrate endothelial lipase (Lipg) were significantly increased by eCG treatment, and the magnitude of response was significantly higher in Pcsk6 ${ }^{\text {tmiRob }}$ mice. Transcript levels for nodal were also increased by eCG in $P c s k 6^{+/+}$mice, but there was no increase observed in Pcsk6 $6^{t m 1 R o b}$ mice. Analysis of PC transcript levels showed that the expression of Pcsk4 was significantly decreased in response to eCG, whereas the expression of Pcsk9 was increased. There was little difference in the basal or eCG-induced expression profile for Pcsk3, Pcsk5, or Pcsk7 (not shown). Moreover, in Pcsk6 ${ }^{+/+}$mice, the expression of Pcsk6 RNA was significantly lower at $48 \mathrm{~h}$ in response to eCG, most likely reflecting the suppressive effects produced by fully grown oocytes as the number of mature antral follicles increases (Diaz et al. 2008). However, Pcsk6 RNA expression returned to basal levels by $60 \mathrm{~h}$ post eCG treatment. The dynamic change in expression suggests a role for select PCs and their substrates during follicle maturation, and demonstrates altered regulation of several hormonally responsive genes in Pcsk ${ }^{\operatorname{tm} 1 R o b}$ mice.

\section{Pcsk6 ${ }^{\text {tm1Rob }}$ female mice exhibit a premature rise in serum FSH levels}

Serum $\mathrm{FSH}$ and $\mathrm{LH}$ were measured in mice ranging from 3 to 15 mo (Table 4). FSH levels remained normal in Pcsk6 $^{+/+}$mice until they were $13-15 \mathrm{mo}$, the age at which these mice show signs of reproductive senescence (Nelson et al. 1982). By contrast, FSH levels were prematurely elevated at 9 mo in Pcsk6 ${ }^{t m 1 R o b}$ mice. No differences in serum LH were identified at any age (Table 4).

\section{Ovaries from Pcsk6 ${ }^{\text {tm1 Rob }}$ mice display abnormal morphologies}

The morphology of ovaries from female mice at 1-20 mo was compared. We observed that there did not appear to be gross abnormalities with any other organ systems,

Table 3 Mean serum steroid levels from saline- or eCG-treated female mice at 48 or $60 \mathrm{~h}$ post injection.

\begin{tabular}{|c|c|c|c|c|}
\hline Genotype & $\begin{array}{l}\text { Treat- } \\
\text { ment }\end{array}$ & $\begin{array}{l}\text { Progesterone } \\
(\mathrm{ng} / \mathrm{ml})\end{array}$ & $\begin{array}{l}\text { Testosterone } \\
(\mathrm{ng} / \mathrm{ml})\end{array}$ & $\begin{array}{c}\text { Estradiol } \\
(\mathrm{pg} / \mathrm{ml})\end{array}$ \\
\hline \multicolumn{5}{|l|}{$48 \mathrm{~h}$} \\
\hline \multirow[t]{2}{*}{ Pcsk6 $6^{+/+}$} & Saline & $3.3 \pm 1.3$ & $42.8 \pm 2.8$ & - \\
\hline & eCG & $15.1 \pm 3.2^{\mathrm{a}}$ & $460.2 \pm 145.4^{\mathrm{a}}$ & - \\
\hline \multirow[t]{2}{*}{ Pcsk6 $6^{\operatorname{tm1Rob}}$} & Saline & $3.4 \pm 0.4$ & $56.34 \pm 8.5$ & - \\
\hline & eCG & $21.3 \pm 3.8^{\mathrm{a}}$ & $392.0 \pm 160.3$ & - \\
\hline \multicolumn{5}{|l|}{$60 \mathrm{~h}$} \\
\hline \multirow[t]{2}{*}{ Pcsk6 $6^{+/+}$} & Saline & $11.20 \pm 3.9$ & $0.1 \pm 0.04$ & $44.4 \pm 8.6$ \\
\hline & eCG & $88.81 \pm 9.7^{\mathrm{a}}$ & $0.9 \pm 0.14^{\mathrm{a}}$ & $137.2 \pm 16.7^{a}$ \\
\hline \multirow[t]{2}{*}{ Pcsk6 $6^{\operatorname{tm1Rob}}$} & Saline & $14.08 \pm 9.1$ & $0.09 \pm 0.007$ & $48.53 \pm 17.3$ \\
\hline & eCG & $63.25 \pm 13.0^{\mathrm{a}}$ & $1.2 \pm 0.2^{\mathrm{a}}$ & $177.9 \pm 14.7^{\mathrm{a}}$ \\
\hline
\end{tabular}

Estradiol was undetectable at $48 \mathrm{~h}$.

${ }^{a}$ Significant difference between saline- and eCG-treated $P<0.01$. 

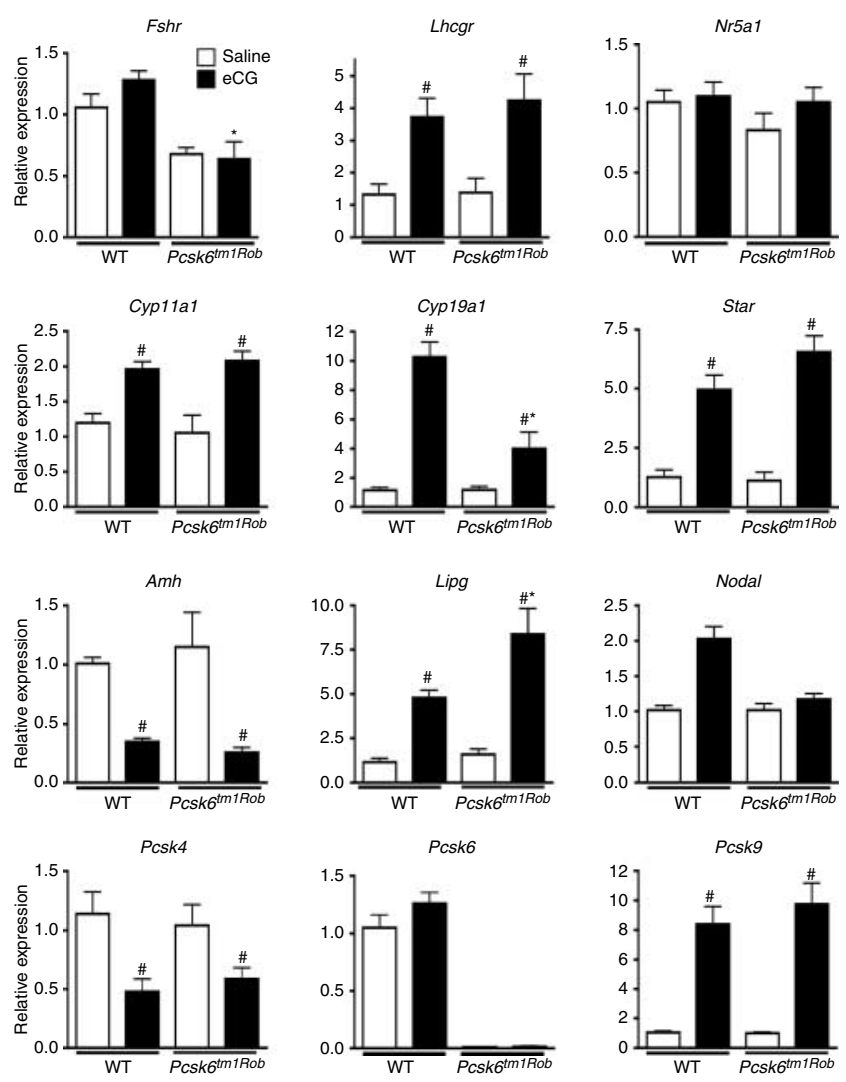

Figure 1 Relative expression $60 \mathrm{~h}$ post eCG injection. Gene expression was analyzed by QPCR in ovaries isolated from 30- to 48-day-old $P_{c s k 6}{ }^{+/+}(\mathrm{WT})$ and Pcsk6 ${ }^{\text {tm1Rob }}$ mice $60 \mathrm{~h}$ post eCG injection. $P_{C s k 6}{ }^{+/+}+\mathrm{PBS}(\mathrm{N}=10), P_{c s k} 6^{+/+}+\mathrm{eCG}(\mathrm{N}=12), P_{c s k} 6^{\text {tm } 1 R o b}+\mathrm{PBS}$ $(N=4), P C s k 6^{t m 1 R o b}+P B S(N=5) .{ }^{\#}$ Significant difference between saline- and eCG-treated groups, * ${ }^{*}$ significant difference between $P_{C s k 6}{ }^{+/+}$and $P$ Csk6 $6^{\text {tmlRob }}$ groups; $P<0.05$.

with the exception that Pcsk6 ${ }^{t m 1 R o b}$ mice are often born with only one eye, the other eye socket being empty. This is consistent with the cyclopia phenotype as part of the complex craniofacial abnormalities observed in e13.5-15.5 embryos as described originally (Constam \& Robertson 2000).

A morphological diagnosis of normal was defined as ovaries containing follicular structures representing the different stages of maturation, corpora lutea, and ovarian surface epithelial and interstitial cells that did not exhibit any unusual features (e.g. hyperplasia). As a normal aspect of the follicle cycle, the presence of degenerating follicles was observed in sexually mature animals from both groups. Prior to $6 \mathrm{mo}$, the majority of ovaries were identified as normal (Fig. 2A and B). Occasionally, interstitial cell hyperplasia with hypertrophy, represented by clusters of large, multinucleated cells with granular cytoplasm, was observed to be present in ovaries of Pcsk6 ${ }^{+/+}$and Pcsk6 ${ }^{\text {tm1Rob }}$ mice starting at 4.5 mo (Fig. 2C and D, arrow). While corpus luteal hyperplasia (Fig. 2E, arrows) and luteomas (Fig. 2F, arrows) were observed in Pcsk6 ${ }^{+/+}$and Pcsk6 ${ }^{t m 1 R o b}$ mice, luteomas were first observed in Pcsk $6^{t m 1 R o b}$ mice starting as early as $3 \mathrm{mo}$; whereas luteomas were only observed in $P_{c s k 6}{ }^{+/+}$mice starting at 9 mo. From 9 mo onward, there was a similar incidence of luteoma formation in both genotypes $\left(P c s k 6^{+/+}=20.6 \% \quad(7 / 34)\right.$ and $\left.P_{c s k} 6^{\text {tm1 Rob }}=23.9 \%(11 / 46)\right)$; however, the Pcsk6 ${ }^{\text {tm1 Rob }}$ ovaries typically displayed additional pathologies, such as cysts or a lack of follicles at any stage.

Approximately, $20 \%$ of $P_{c s k} 6^{\operatorname{tm} 1 R o b}$ mice between 6 and 14 mo had ovaries with normal histological features similar to those from age-matched Pcsk6 $6^{+/+}$mice (Fig. 3A). The majority of the ovaries from Pcskb ${ }^{\text {tm1Rob }}$ animals displayed complex morphologies including an apparent reduction or absence of follicles (Fig. 3B-E), ovarian atrophy (Fig. 3C), proteinaceous (Fig. 3E) or hemorrhagic (Fig. 3F) cysts in the presence or absence of follicles, and epithelial inclusion cysts (Fig. 3G and H). The lumen of cysts was typically lined with one to five cell layers of columnar or cuboidal epithelial cells (Fig. $3 \mathrm{H})$. Small proteinaceous cysts were occasionally observed in $P_{c s k 6}{ }^{+/+}$mice prior to $14 \mathrm{mo}(n=4 / 46)$, but healthy follicles representing the different stages of maturation were always present in these ovaries.

The most severely affected ovaries from Pcsk6 ${ }^{\operatorname{tm} 1 \text { Rob }}$ mice exhibited complete ovarian atrophy with a lack of follicular structures (Fig. 3C). Furthermore, $\sim 11 \%$ (11/97) of the Pcsk6 $6^{\text {tm1Rob }}$ animals developed tubulostromal adenomas, composed of a mass of dilated tubules lined by non-ciliated cuboidal epithelium (Fig. 4A and B). These structures were typically separated by various sized large round to polygonal cells resembling stromal interstitial cells. Other benign tumors, such as cystadenoma ( $n=5$; Fig. $4 \mathrm{C}$ and D) or granulosa cell tumor $(n=2$; Fig. 4E and F), were also identified. Normal ovarian architecture was typically obliterated in Pcsk6 ${ }^{\text {tm1Rob }}$ mice presenting with tubulostromal adenoma, cystadenoma, or granulosa cell tumors. As was the case with the original females used to establish the colony (Supplementary Figure 2 and Supplementary Table 1, see section on supplementary data given at the

Table 4 Mean serum FSH and LH levels.

\begin{tabular}{|c|c|c|c|c|}
\hline $\begin{array}{l}\text { Age } \\
\text { (months) }\end{array}$ & $n$ & Genotype & $\begin{array}{c}\text { Mean FSH } \\
\pm \text { s.E.M. }(\mathrm{ng} / \mathrm{ml})\end{array}$ & $\begin{array}{c}\text { Mean LH } \\
\pm \text { s.E.M. }(\mathrm{ng} / \mathrm{ml})\end{array}$ \\
\hline \multirow[t]{2}{*}{$3-6$} & 15 & Pcsk6 $^{+/+}$ & $9.1 \pm 1.8$ & $1.4 \pm 0.4$ \\
\hline & 12 & PCsk6 $6^{\text {tm1Rob }}$ & $17.9 \pm 7.4$ & $0.9 \pm 0.3$ \\
\hline \multirow[t]{2}{*}{$7-8$} & 7 & $P_{c s k 6}{ }^{+/+}$ & $6.9 \pm 0.7$ & $0.4 \pm 0.08$ \\
\hline & 14 & $P_{c s k} 6^{\operatorname{tm1Rob}}$ & $13.4 \pm 5.4$ & $0.7 \pm 0.1$ \\
\hline \multirow[t]{2}{*}{9} & 9 & $P_{c s k 6}{ }^{+/+}$ & $10.8 \pm 5.4$ & $0.7 \pm 0.1$ \\
\hline & 11 & PCsk6 $\sigma^{\text {tm1Rob }}$ & $33.8 \pm 8.9^{\mathrm{a}}$ & $0.8 \pm 0.2$ \\
\hline \multirow[t]{2}{*}{$10-12$} & 10 & Pcsk6 $^{+/+}$ & $7.3 \pm 0.9$ & $0.8 \pm 0.1$ \\
\hline & 17 & Pcsk6 ${ }^{\operatorname{tm1Rob}}$ & $36.3 \pm 8.3^{\mathrm{a}}$ & $1.3 \pm 0.6$ \\
\hline \multirow{2}{*}{$13-15$} & 13 & $P_{\text {csk6 }}{ }^{+/+}$ & $33.8 \pm 5.7$ & $0.9 \pm 0.3$ \\
\hline & 15 & PCsk6 $\sigma^{\operatorname{tm} 1 R o b}$ & $43.7 \pm 4.5$ & $0.9 \pm 0.2$ \\
\hline
\end{tabular}

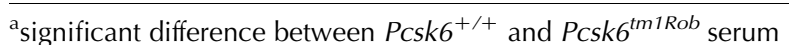
levels, $P<0.05$. 
A

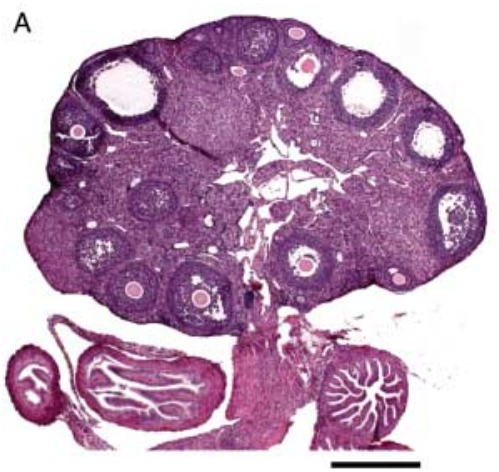

C
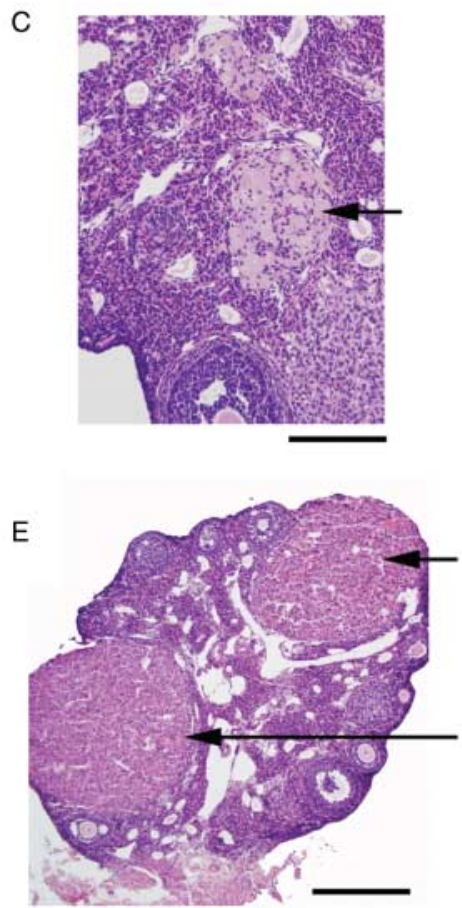

B

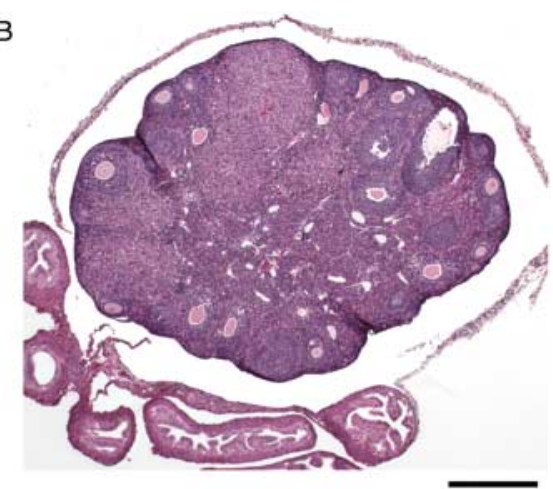

D

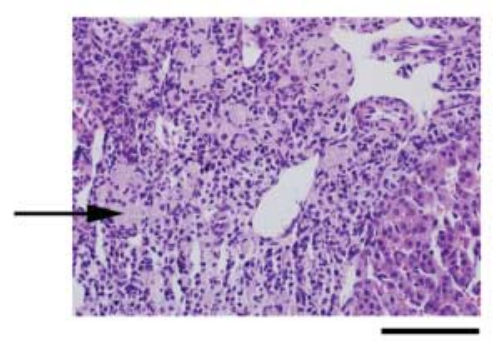

$\mathrm{F}$

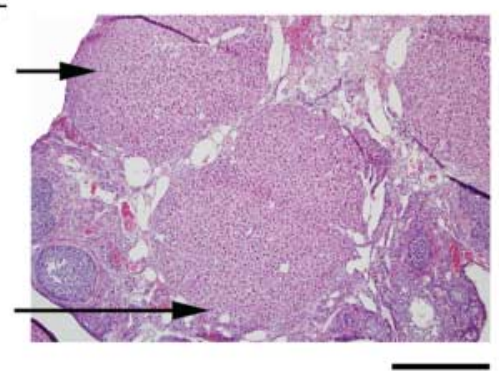

Figure 2 Ovarian morphology common in Pcsk6 $^{+/+}$and Pcsk6 ${ }^{\text {tm1Rob }}$ mice. Representative images of normal ovarian morphology in Pcsk6 $^{+/+}$(A) and Pcsk6 ${ }^{\text {tm1Rob }}$ (B) mice at 3 mo. Interstitial cell hyperplasia and hypertrophy were observed in some 4.5-month-old Pcsk6 ${ }^{+/+}$ (C) and Pcsk6 ${ }^{\text {tm1 } 1 R o b}$ (D) mice (arrows). Corpora luteal hyperplasia (E) and multiple luteomas (F) were also observed in both Pcsk6 $6^{+/+}$and Pcsk6 ${ }^{\text {tm1Rob }}$ mice (arrows). (E) Pcsk6 ${ }^{+/+}$mouse at 6 mo. (F) Pcsk6 ${ }^{\text {tm1Rob }}$ at 4 mo mouse. Scale bars are indicated with a line below the image. For $\mathrm{A}$ and $\mathrm{B}$, the scale bar is equivalent to $800 \mu \mathrm{m} ; \mathrm{C}$ and $\mathrm{D}, 50 \mu \mathrm{m} ; \mathrm{E}$ and $\mathrm{F}, 600 \mu \mathrm{m}$. end of this article), many Pcsk6 $6^{\text {tm1Rob }}$ animals that were fertile were found to possess abnormal ovarian morphologies after they were harvested (Figs 3B, C, E, $4 \mathrm{~A}$ and $\mathrm{C}$ ). However, Pcsk $6^{\text {tm1Rob }}$ mice often reached reproductive senescence at an earlier age than $P c s k 6^{+/+}$ littermates ( $\sim 8 \mathrm{mo})$. After $14 \mathrm{mo}$, ovarian atrophy was commonly observed in all animals. No adenomas or granulosa cell tumors were identified in any Pcsk6 $6^{+/+}$ animals up to 20 mo.

\section{Aging Pcsk6 ${ }^{-1-}$ female mice exhibit differential expression of genes that contribute to reproductive function}

To obtain further insight into biochemical pathways or effector molecules that may be altered in aging mice, total RNA isolated from one ovary of estrus stagematched 6-mo-old Pcsk6 ${ }^{+/+}$and Pcsk6 ${ }^{\text {tm1Rob }}$ female mice was used for QPCR analysis (four animals in each group; Table 5). This age was selected because gross morphological differences were typically not detected prior to $6 \mathrm{mo}$, and we hypothesized that this time point might provide an expression profile reflective of molecular alterations preceding gross morphological changes. Mild interstitial cell hyperplasia was observed in the contralateral ovary of one $P_{c s k 6}{ }^{+/+}$mouse (Fig. 3C) and two Pcsk6 tmiRob mice, but the others were morphologically indistinguishable. These analyses identified changes in expression of genes associated with gonadotropin signaling, steroid hormone production, or reproductive growth factors. For example, Fshr expression was increased 2.4-fold, which correlated with increased expression of downstream targets including LH receptor (Lhcgr) and Cyp19a1, 5.0- and 6.2-fold respectively. At $6 \mathrm{mo}, \mathrm{Nr} 5 \mathrm{a} 1 \mathrm{RNA}$ expression was elevated $\sim 2.5$-fold in the $P c s k 6^{t m 1 R o b}$ ovaries relative to the $P c s k 6^{+/+}$mice, whereas no detectable increase was observed in $\mathrm{Nr} 5 \mathrm{a} 2$. 
A

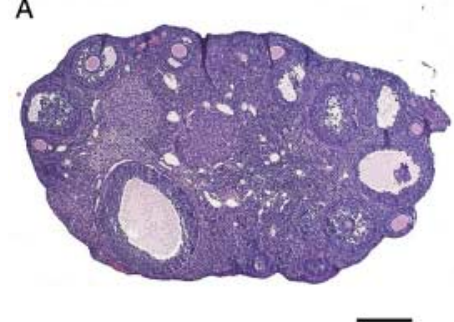

C

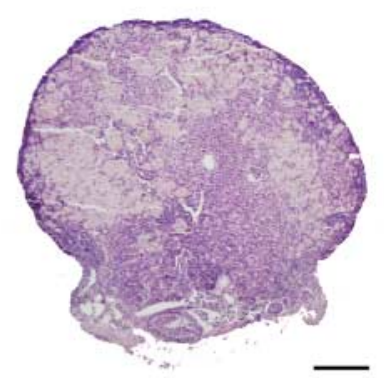

E

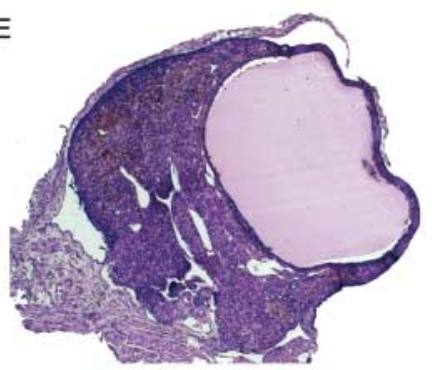

G

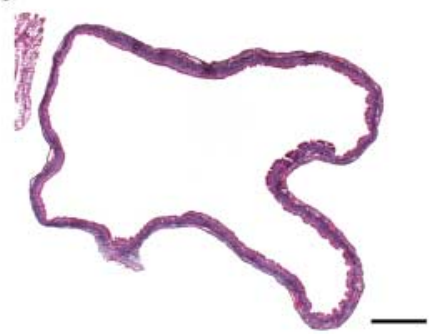

B

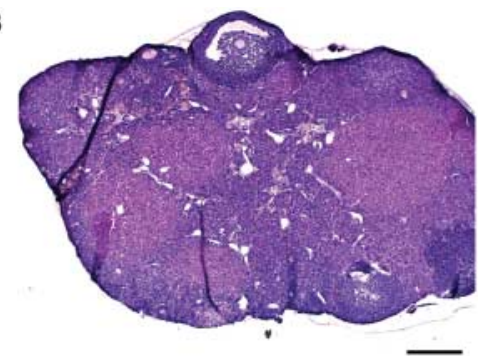

D

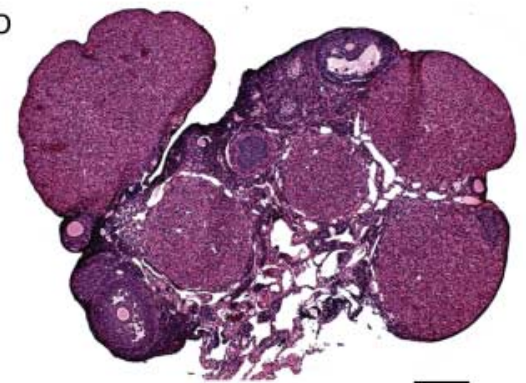

$\mathrm{F}$

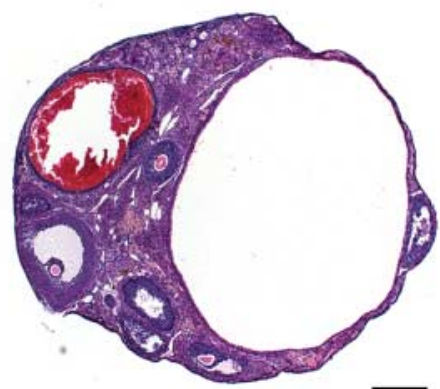

$\mathrm{H}$

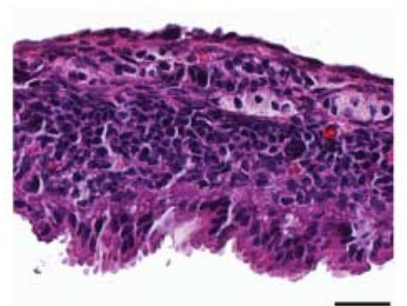

Figure 3 Variations of ovarian morphology exhibited by Pcsk6 ${ }^{t m 1 R o b}$ mice. Representative $\mathrm{H} \&$ E-stained ovarian sections from $P_{c s k} 6^{+/+}$and Pcsk6 ${ }^{t m 1 R o b}$ mice are shown. (A) Pcsk6 ${ }^{+/+}$ mouse at 9 mo (\#27). (B-E) Pcsk6 $6^{\text {tm } 1 R o b}$ mice at 9 mo exhibit mild (B; mouse \#33) to severe (C; mouse \#1260) ovarian atrophy with a reduced number of follicles relative to age-matched mice, a disorganized ovarian organ structure with corporal luteal hyperplasia and minimal interstitial tissue (D; mouse \#134), ovarian atrophy with proteinaceous cystic follicles (E; mouse $\# 9$ ), hemorrhagic cysts (F; mouse \#1152, 12 mo), and epithelial inclusion cysts ( $F$ and G). (G) Tissues representing the right and left ovaries of mouse $\# 1254$ (9 mo). There is a complete absence of stroma and mesenchymal structures for the right ovary replaced by a single large cyst-like structure lined by one (bottom panel) to multiple (top panel) cell layers of columnar epithelium $(H)$. The left ovary exhibits interstitial cell hyperplasia, follicular degeneration, and dilated follicular cysts lined by one cell layer thick epithelium. Scale bars are indicated with a line below the image. For A, B, C, D, and F, the scale bar is equivalent to $400 \mu \mathrm{m} ; \mathrm{E}, 125 \mu \mathrm{m} ; \mathrm{G}$, $500 \mu \mathrm{m} ; \mathrm{H}, 50 \mu \mathrm{m}$.
Embryologically, proteolytic processing of nodal by PCSK6 and PCSK3 are required to promote autoregulation of Nodal transcription (Beck et al. 2002). Total RNA levels of Nodal remained the same in Pcsk6 ${ }^{+/+}$and Pcsk6 ${ }^{\operatorname{tm} 1 R o b}$ ovaries at baseline, suggesting that inactivation of PCSK6 alone is insufficient to alter Nodal autoregulation. By contrast, expression of Lipg was reduced by $92 \%$ in Pcsk6 ${ }^{\text {tmiRob }}$ ovaries. Analysis of PC expression indicated that Pcsk3 and Pcsk4 were reduced, Pcsk9 was lower, but not significantly, and Pcsk5 and PCsk7 were unaffected. The expression of several signaling molecules (Wnt4, epiregulin, and Bmp4) and signaling regulators (Sfrp4 and Grem1) was also significantly altered in ovaries from Pcsk6 $6^{\text {tmiRob }}$ mice. Collectively, these expression data indicate that changes occur at the molecular level in Pcskb ${ }^{\operatorname{tm} 1 \text { Rob }}$ ovaries that affect proteins involved in a number of cellular processes in multiple ovarian cell types prior to the formation of gross pathologies.

\section{Discussion}

This study establishes the expression of the Pcsk6 gene as a contributor to the maintenance of ovarian physiology and tissue integrity in aging $\mathrm{C} 57 \mathrm{BI} / 6$ mice. To date, there has been no postnatal phenotype described for the $\sim 75 \%$ of viable $P c s k 6^{t m i R o b}$ animals. Prior to $6 \mathrm{mo}$, the ovaries of $P c s k 6^{t m 1 R o b}$ mice are typically indistinguishable from $P_{c s k 6}{ }^{+/+}$littermates at the level of their gross anatomy. Pcsk6 ${ }^{\text {tm1Rob }}$ mice are fertile and efficiently 
A

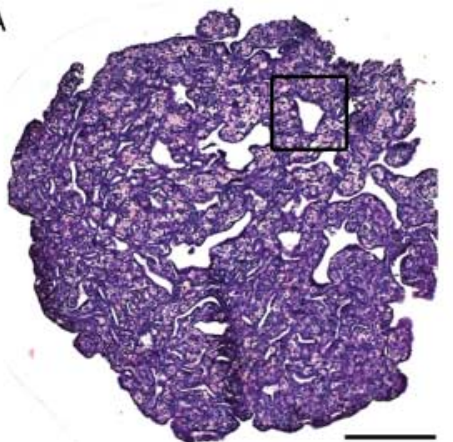

C

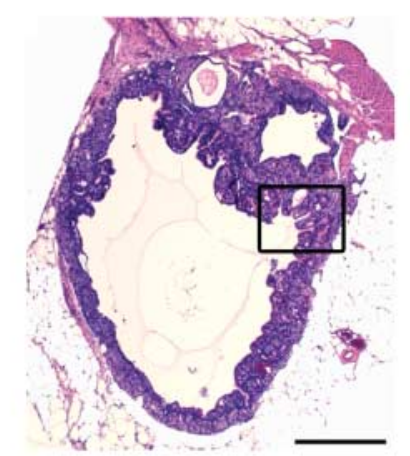

E

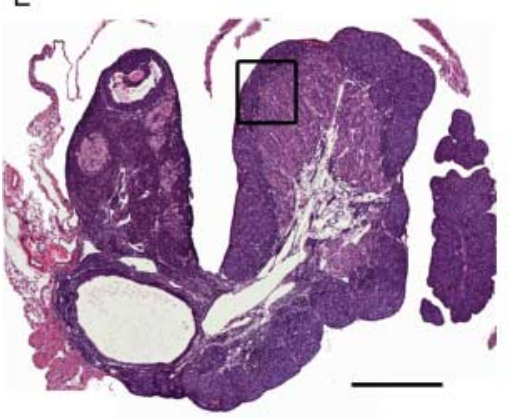

B

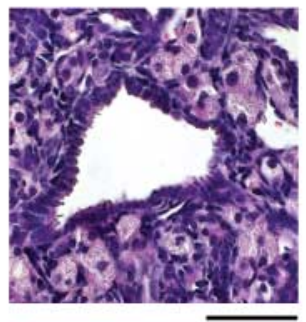

D

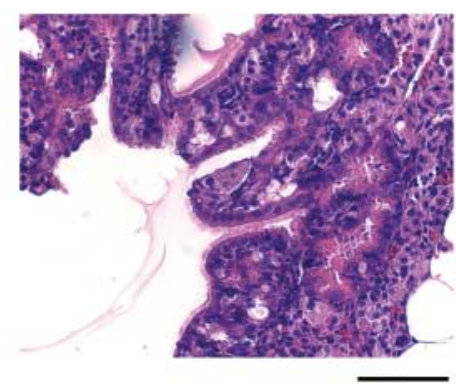

$\mathrm{F}$

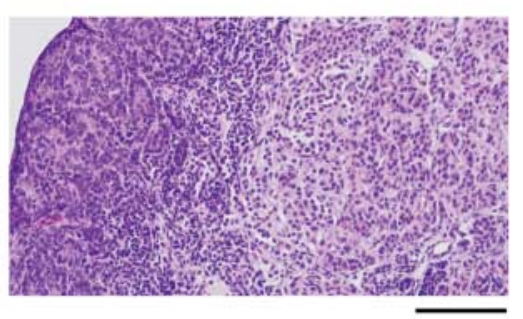

Figure 4 Benign tumor phenotypes of Pcsk $6^{t m 1 R o b}$ mice. Representative H\&E-stained ovarian sections from Pcsk6 $6^{\text {tm1Rob }}$ mice are shown. (A) Tubulostromal adenoma in a 7-mo mouse (\#32). This tissue mass is comprised of acinar and tubular epithelial structures, with no detectable normal ovarian features. The boxed area is shown in (B) at higher magnification; this depicts an inclusion cyst lined by ciliated columnar epithelium. (C) The right ovary of mouse \#118 (13 mo) exhibits a cystadenoma, with no detectable normal ovarian features. Papillary projections are lined by ciliated epithelial cells (higher magnification shown in (D)). The left ovary of mouse \#118 exhibited severe interstitial cell hyperplasia, a hemorrhagic cyst, and a tubulostromal adenoma. (E) The left ovary of mouse \#1327 (13.5 mo) exhibits some follicular structures, in addition to a large epithelial cyst, and a granulosa cell tumor (higher magnification in F). The tumor is composed of nests of epithelial cells ranging in morphology from large cells with a pale, foamy cytoplasm to small, elongated cells that form tubule-like structures or large nests of cuboidal or polygonal cells with large basal ovalshaped nuclei. The right ovary of mouse \#1327 was severely atrophied and scattered throughout, and there are frequent individual nests of cells similar to those described for the left ovary. There was also one dilated and hemorrhagic follicle and several small degenerate follicles. For $A$, the scale bar is equivalent to $250 \mu \mathrm{m} ; \mathrm{B}, 25 \mu \mathrm{m} ; \mathrm{C}, 800 \mu \mathrm{m}$; $\mathrm{D}$ and $\mathrm{F}, 50 \mu \mathrm{m} ; \mathrm{E}, 1000 \mu \mathrm{m}$. raise pups to weaning, thus they possess the adequate follicular, endocrine, and neuroendocrine parameters for reproductive competence. However, at early ages, molecular abnormalities are evident in their altered responses to exogenous hormone. By 6 mo, ovarian gene expression profiles are significantly different from Pcsk6 $^{+/+}$animals indicating molecular alterations prior to formation of pathology. As the animals age beyond $6 \mathrm{mo}$, there is an increase in serum FSH levels corresponding with reduced estrous cyclicity. In the most extreme scenarios, normal ovarian structures were absent and often replaced by large cysts or benign tumors. We hypothesize that the loss of PCSK6 activity produces an imbalance in substrate levels that is not fully compensated by other PC activity, resulting in the myriad of cellular and molecular changes displayed by the Pcsk6 ${ }^{\text {tm1Rob }}$ mice.

Pcsk6 is expressed in theca cells at all stages of follicle maturation and granulosa cells prior to the antral stage
(Diaz et al. 2008). FSH increases Pcsk6 RNA in preantral granulosa cell-oocyte complexes, and RNA expression is subsequently suppressed by oocyte-derived factors in antral follicles (Diaz et al. 2008). The phenotypic effects that we observed are likely due to altered substrate activity in preantral follicle granulosa cells and potentially any stage of follicle maturation in theca cells. Between 30 and 48 days of age, Pcsk ${ }^{t m 1 R o b}$ mice are capable of responding to exogenous eCG showing the expected alterations in gene expression and enhanced steroid production. However, the basal level or degree of response of some genes is less in the Pcsk $6^{t m 1 R o b}$ ovaries than that in the Pcsk6 ${ }^{+/+}$mice, e.g. Fshr and Cyp19a1. Of course, variation in gene expression levels may be due to changes in the number of cells expressing the transcript, transcriptional regulation, or RNA stability. Our data raise the possibility that there are inherent alterations in granulosa and theca cells of Pcsk $6^{\operatorname{tm} 1 R o b}$ mice that contribute to the reproductive abnormalities 
Table 5 Relative fold gene expression in whole ovary of estrus stagematched Pcsk6 ${ }^{\text {tm1Rob }}$ compared with $P_{c s k 6}{ }^{+/+}$mice at 6 months of age.

\begin{tabular}{lll}
\hline Gene & Synonym & $\begin{array}{l}\text { Mean expression } \\
\text { relative to } \\
\text { Pcsk6 }^{+/+}( \pm \text {s.E.M. })\end{array}$ \\
\hline Nr5a1 & Steroidogenic factor 1 & $2.5 \pm 0.8^{*}$ \\
Nr5a2 & Liver receptor homolog-1 & $1.1 \pm 0.17$ \\
Fshr & FSH receptor & $2.4 \pm 0.8^{*}$ \\
Lhcgr & LH/choriogonadotropin receptor & $5.0 \pm 0.7^{*}$ \\
Cyp11a1 & P450 side chain cleavage & $0.7 \pm 0.4$ \\
Hsd3b & P450 hydroxysteroid dehydrogenase & $1.2 \pm 0.6$ \\
& 3 beta & $6.8 \pm 2.6^{*}$ \\
Cyp17a1 & Cyp17a1 & $6.2 \pm 1.8^{*}$ \\
Cyp19a1 & P450 aromatase & $1.4 \pm 0.8$ \\
Star & Steroidogenic acute regulatory protein \\
Ptgs1 & Cyclooxygenase 1 & $0.76 \pm 0.2$ \\
Ptgs2 & Cyclooxygenase 2 & $1.6 \pm 0.7^{\mathrm{a}}$ \\
Sfrp4 & Secreted frizzled-related protein 4 & $0.22 \pm 0.07^{*}$ \\
Wnt4 & Wingless-related MMTV integration & $0.45 \pm 0.05^{*}$ \\
& site 4 & $1.01 \pm 0.08$ \\
Amh & Anti-Müllerian hormone & $0.6 \pm 0.1$ \\
Ereg & Epiregulin & $1.01 \pm 0.45$ \\
Areg & Amphiregulin & $0.53 \pm 0.04^{*}$ \\
Bmp4 & Bone morphogenetic protein 4 & $0.49 \pm 0.14$ \\
Bmp6 & Bone morphogenetic protein 6 & $2.65 \pm 0.08$ \\
Grem1 & Gremlin & $1.06 \pm 0.21$ \\
Nodal & Nodal & $0.08 \pm 0.008^{*}$ \\
Lipg & Endothelial lipase & $0.52 \pm 0.04^{*}$ \\
Pcsk3 & Furin & $0.53 \pm 0.2$ \\
Pcsk4 & Proprotein convertase 4 & $0.9 \pm 0.2$ \\
Pcsk5 & Proprotein convertase 5 & $0.75 \pm 0.13$ \\
Pcsk7 & Proprotein convertase 7 & $0.6 \pm 0.2$ \\
Pcsk9 & Proprotein convertase 9 & Standard for \\
rpll & RNA polymerase II & $10 a d i n g$ \\
& & \\
\hline & &
\end{tabular}

Ovaries from four age-matched and estrus stage-matched animals were used for each genotype. Data represents fold differences of pooled data for each genotype. ${ }^{*} P<0.01$.

${ }^{a}$ Three of four Pcsk6 ${ }^{t m 1 R o b}$ mice had increased Ptgs2 expression averaging 1.6-fold compared to wild-type mice, whereas one PCsk6 ${ }^{\text {tmiRob }}$ mouse showed $>20$-fold overexpression.

observed, including increased whelping interval and reduced estrus cyclicity. The fact that we do observe alterations in the responses for some (e.g. Fshr, Cyp19a1, Nodal), but not all (e.g. Lhcgr, Nr5a1, Cyp11a1, Pcsk4, Pcsk9), genes suggests that at the early ages examined, a difference in follicle cell number is unlikely to account for these changes. Moreover, the direction of the alteration between the $P c s k 6^{+/+}$and $P_{c s k} 6^{\text {tm1Rob }}$ mice is not always in the same direction, i.e. we do not always observe a decrease in the Pcsk6 $6^{t m 1 R o b}$ animals suggestive of decreased cell numbers, sometimes there is an increase in gene expression (e.g. Lipg). As the animals age, more defects are apparent with increased serum $\mathrm{FSH}$ and alterations in basal gene expression. As these reproductive parameters are dependent on the production of protein and steroid hormones from healthy ovarian follicles, the aberrant physiological responses in Pcsk6 ${ }^{\text {tm1Rob }}$ mice are most likely due to loss of negative endocrine feedback or changes in the local autocrine/ paracrine milieu that compromise follicle health.
We observed elevated FSH levels starting at 9 mo of age in the Pcsk6 ${ }^{t m 1 R o b}$ mice, reflective of a loss of endocrine feedback. Mice engineered to overexpress FSH under the direction of the metallothionein-1 promoter develop hemorrhagic and fluid-filled cysts; however, these mice develop ovarian pathology by $6-7$ weeks (Kumar et al. 1999). It thus remains possible that the higher levels of FSH observed contribute to the formation of cystic phenotype in Pcsk6 $6^{t m 1 R o b}$ mice. Future studies to conduct morphometric analysis of follicle loss and experiments using granulosa cells isolated from different stages of follicle maturation will provide greater insight into disruptions produced by loss of PCSK6 activity.

The phenotypes observed in the Pcsk $6^{t m 1 R o b}$ ovaries are unlike many other single gene knockout or transgenic models described (Matzuk \& Lamb 2002, Vanderhyden et al. 2003). Reduced oocyte number or accelerated oocyte loss is a precursor to pathologies observed in different mouse models (Matzuk \& Lamb 2002, Vanderhyden et al. 2003, Vanderhyden 2005). In general, ovarian follicle depletion is associated with increased epithelial invaginations and inclusion cysts, as well as with formation of tubular adenomas. Invasive epithelial tubules and tubulostromal adenomas develop in the vast majority of mice with germ cell deficiencies, such as those produced by mutations in the $W($ Kit) or SI (Kitl) loci (Murphy 1972, Murphy \& Beamer 1973, Ishimura et al. 1986, Vanderhyden et al. 2003). These abnormalities typically form by 7 mo and are directly correlated with oocyte depletion. Pcsk6 ${ }^{\text {tm1Rob }}$ ovaries are frequently observed with a reduced number or complete absence of oocytes strongly suggesting that loss of oocytes participates in the formation of the tubular adenomas. Pcsk $6^{\text {tm1Rob }}$ ovaries exhibit other benign tumor types including granulosa cell tumors or cystadenomas. Development of these pathologies indicates that substrates cleaved by PCSK6 likely play a role in aspects of ovarian cell function and survival.

The histopathological phenotype of the Pcsk $6^{\operatorname{tm} 1 R o b}$ ovaries is variable, indicating that there is incomplete penetrance of the phenotype produced by inactivation of the Pcsk6 gene. This is consistent with the observations made in the original description of the Pcsk6 $6^{\operatorname{tm} 1 R o b}$ mouse, where multiple phenotypes resulting in embryonic lethality were produced in only $25 \%$ of the offspring (Constam \& Robertson 2000). Constam \& Robertson (2000) originally proposed that functional overlap between PCSK3 (furin) and PCSK6 might account for incomplete penetrance of the Pcsk ${ }^{\text {tmPRob }}$ phenotype. Unfortunately, inactivation of Pcsk3 (Roebroek et al. 1998) produces $100 \%$ embryonic lethality, thus precluding the opportunity to study the contribution of Pcsk3 in ovarian biology using a standard knockout model. Quantification of other PC transcripts at 6 mo suggests that loss of PCSK6 activity does not induce a mechanism to produce a compensatory increase in PC 
transcription. Indeed, basal levels of Pcsk3, Pcsk4, and Pcsk7 were decreased in Pcsk6 $6^{\text {tm1Rob }}$ ovaries at 6 mo. Reduced expression of these PCs, and thus altered bioactive substrate levels, may contribute further to an abnormal cellular environment leading to the observed ovarian phenotypes.

Many of the genes that encode proteins participating in ovarian reproductive activities are regulated through signaling pathways that often converge with the $\mathrm{Sf}-1$ and Lrh-1 transcription factors. At 6 mo, Nr5a1 (Sf-1) RNA expression was elevated $\sim 2.5$-fold in the Pcsk6 ${ }^{-1-}$ ovaries relative to the $P$ csk $6^{+/+}$mice, whereas no detectable increase was observed in Nr5a2 (Lrh-1). Expression of Fshr, an Sf-1-regulated gene (Levallet et al. 2001), was increased 2.4-fold. As anticipated, the RNA for a downstream target of FSH signaling, Cyp19a1, was also increased. There was no detectable change in additional genes associated with steroidogenesis, Star, Cyp11a1, or Hsd3b. The RNA of a luteal marker, Sfrp4, an inhibitor of WNT signaling (Kawano \& Kypta 2003), was dramatically decreased. Collectively, these data show that there are significant changes in the RNA expression of transcriptional regulators, signaling inhibitors, and rate-limiting enzymes that may contribute to the formation of an abnormal environment in Pcsk6 ${ }^{t m 1 R o b}$ ovaries leading to the formation of pathologies contributing to reduced reproductive capacity.

We also evaluated the expression levels of the PCSK6 substrates nodal and endothelial lipase. Nodal is a TGFB/BMP superfamily member that induces granulosa cell apoptosis, thus likely playing a role in follicular atresia (Wang et al. 2006). Nodal controls its own mRNA expression through an autoregulatory activity, which requires efficient nodal maturation via PCSK3 and PCSK6 proteolysis (Beck et al. 2002). The presence of either PCSK3 or PCSK6 is sufficient to cleave immature nodal. No differences in Nodal mRNA expression were measured in Pcsk6 ${ }^{\text {tm1Rob }}$ compared with Pcsk6 ${ }^{+/+}$ animals at basal levels; however, nodal expression was not induced by eCG in Pcsk ${ }^{\text {tmiRob }}$ ovaries compared with Pcsk6 ${ }^{+/+}$ovaries. We hypothesize that PCSK6 activity is required for nodal induction but is dispensable to maintain basal RNA expression levels. Unfortunately, antibodies to detect endogenous nodal protein are poor, and so we are currently unable to examine the degree of nodal maturation in the Pcskb $6^{\text {tmiRob }}$ ovary. Nodal activity is required to sustain Bmp4 expression embryologically (Beck et al. 2002). We theorize that Bmp4 RNA levels are lower because of reduced nodal maturation occurring through absent PCSK6, and reduced PCSK3, activity. Further investigation will be required to determine if nodal maturation is efficiently accomplished in Pcsk ${ }^{t m 1 R o b}$ ovaries, and the effects that this may have on BMP activity.

Endothelial lipase is a member of the triglyceride lipase family and is tethered to the plasma membrane through heparan sulfate proteoglycans, where it metabolizes high-density lipoprotein (HDL) particles allowing cholesterol ester uptake (Broedl et al. 2003, Fuki et al. 2003). Limited analysis of endothelial lipase expression in reproductive tissues demonstrate low levels of expression in the non-pregnant ovary and high levels in the pregnant ovary localized to the corpus luteum (Lindegaard et al. 2005). In a model examining human endothelial lipase expression in a transgenic mouse, the ovary was one of the sites of highest expression (Broedl et al. 2005). There is no mention in this study as to whether endothelial lipase is expressed in specific ovarian cell types. Our experiments revealed that Lipg RNA is increased in response to exogenous $\mathrm{eCG}$, indicating that this gene product is likely needed for enhanced cholesterol uptake during a time when steroid production is increased. Moreover, at 30-48 days of age, Lipg RNA levels increased significantly more in response to eCG in Pcsk6 ${ }^{\text {tm1Rob }}$ ovaries compared with wild-type animals. Since PCSK6 proteolytically cleaves endothelial lipase to reduce lipase activity, the increased RNA levels in Pcsk6 $6^{t m 1 R o b}$ ovaries are unlikely due to a compensatory transcriptional response because of reduced bioactive protein levels. This is in contrast to increased levels of pituitary adenylate cyclase-activating polypeptide transcripts that were observed in the ovaries and testes of Pcsk4 null animals (Li et al. 2000). Additional research will be required to investigate the underlying cause of the enhanced eCG response in PCsk6 ${ }^{\text {tm1Rob }}$ ovaries.

We further identified a dramatic decrease in ovarian endothelial lipase ( $L i p g$ ) RNA levels in Pcsk6 $6^{\text {tm1Rob }}$ ovaries (0.08-fold expression) at $6 \mathrm{mo}$, and hypothesized that as the animals age, the loss of Lipg expression compromises cholesterol metabolism contributing to aberrant cell physiology. It is unclear how a loss of PCSK6 activity may result in decreased endothelial lipase RNA expression in the ovary. Endothelial lipase expression can be regulated through peroxisome proliferator-activated receptor (PPAR) $\alpha$ activity (Ahmed et al. 2006, Rakhshandehroo et al. 2007). Ahmed et al. (2006) have demonstrated that PPAR $(\alpha>>\gamma>\delta)$ activity is increased by endothelial lipase-mediated HDL hydrolysis. While there is an abundance of evidence to support a role for PPARs in normal reproduction (Froment et al. 2006), there is currently no evidence linking PCSK6 protein activity with PPAR activity. This will be the focus of future research. Decreased endothelial lipase expression was not restricted to the Pcsk6 ${ }^{\text {tmiRob }}$ ovary alone. We also measured decreased expression in abdominal adipose tissue; however, there was no change in endothelial lipase mRNA levels in the liver compared with Pcsk6 ${ }^{+/+}$ mice, suggesting that the mechanisms regulating endothelial lipase activity are tissue specific (QPCR data not shown).

We discovered that the expression of Pcsk4, Pcsk6, and Pcsk9 are altered by exogenous eCG, strongly 
suggesting that PC expression is regulated during the process of follicle maturation. Given the myriad of changes in PC substrate production that occurs during the process of follicle maturation, e.g. growth factors, growth factor receptors, and integrins, it is logical to expect that PC expression is capable of responding to changes in substrate levels. There is precedence for PC levels changing in response to endocrine signals, or for substrate levels changing when PCs are inactivated. In rats, it was shown that anterior pituitary Pcsk6 expression is dependent on thyroid status, low under hypothyroid conditions and high with excess thyroid hormone (Johnson et al. 1994). Male and female Pcsk4 knockout mice exhibit increased RNA levels of propituitary adenylate cyclase-activating peptide, a known PCSK4 substrate ( $\mathrm{Li}$ et al. 2000). Our research shows that changes in Pcsk6 expression result in alterations in the basal level of ovarian Pcsk4 and Pcsk9 RNA at $6 \mathrm{mo}$, and we believe that these changes are due to either an alteration in PCSK6 substrate activity or a change in the number or activity of the cells expressing these enzymes. PCSK4 production is localized to ovarian theca, interstitium, and corpora luteal cells (Tadros et al. 2001). Importantly, female Pcsk4 knockout mice are subfertile and show reduced increase in ovarian weight and $\mathrm{P}_{4}$ production following eCG treatment (Tadros et al. 2001). Thus, the reduced Pcsk4 expression profile observed in Pcsk6 $6^{\text {tm1Rob }}$ mice at 6 mo is one more indication of compromised ovarian health. We hypothesize that with age, the loss of Pcsk6 activity establishes an imbalance in substrate activity for which the ovarian cells cannot compensate leading to detrimental changes in ovarian cell biology.

The mechanism(s) underlying how the loss of PCSK6 protease activity results in altered gene expression, hormone production, and tissue morphology remains to be determined. This initial investigation lays the foundation to assess the relationship between PCSK6 expression and these molecular and cellular processes. This study shows that the Pcsk $6^{t m 1 R o b}$ mouse provides a platform to examine ovarian pathologies. A rise in serum $\mathrm{FSH}$ is the most sensitive and widely accepted early marker for ovarian failure (Conway 2000). The observed alterations in FSH secretion coinciding with reduced fertility and decreased follicle number suggest that PCSK6 may also contribute to human diseases including infertility and premature ovarian insufficiency. The Pcsk6 $6^{t m} R o b$ mouse offers a platform to experimentally investigate mechanisms of reproductive failure, including the contributions of the oocyte and somatic cells to maintain follicle health, the identity and bioactive state of the substrates that regulate these cellular activities, and the signaling pathways or functional activities that are affected via disruption of substrate processing.

Our previous research also demonstrated a reduction or absence of Pcsk6 RNA in human ovarian cancer cell samples (Fu et al. 2003), and this observation was confirmed by Page et al. (2007). Indeed, we determined that PCSK6 gene expression is reduced due to epigenetic modification of the $5^{\prime}$-flanking DNA and first exon in human ovarian cancer patient cell samples (Fu et al. 2003). As Pcsk6 ${ }^{t m 1 R o b}$ ovaries can develop cellular aberrations and tumors similar to precursor lesions in human tumors, we predict that an alteration in PC activity, increased or decreased, resulting in changes in the activity of proteins contributing to cellular stability is likely to contribute to the formation or progression of human ovarian cancers. Page et al. (2007) have shown that increased expression of Pcsk3 was correlated with decreased survival in a subset of ovarian cancer patients. Although they did not show a correlation between decreased Pcsk6 RNA levels and survival, this does not preclude the possibility that reduced Pcsk6 expression contributes to ovarian cancer etiology through reduced bioactivation or inactivation of substrates critical to maintain cellular homeostasis. Indeed, given the myriad of phenotypes displayed by the Pcsk $6^{\text {tm1Rob }}$ ovary, it is suggested that PCSK6 activity should be examined in human ovarian pathology to ascertain further the clinical role that altered PC activity may contribute to human reproductive disease.

\section{Materials and Methods}

\section{Animals}

Animals were maintained according to the Canadian Council on Animal Care, and institutional approval for research with animals was received prior to the initiation of these studies (Protocol 09-002). All animals were maintained in a temperature-controlled environment at $22{ }^{\circ} \mathrm{C}$ on a $12 \mathrm{~h}$ light: $12 \mathrm{~h}$ darkness schedule and provided with food and tap water ad libitum. Generation and genotyping of mice with a targeted disruption of the Pcsk6 gene was described previously (Constam \& Robertson 2000). Crosses of Pcsk6 $6^{\text {tm1Rob/+ }}$ mice produced progeny in the expected ratio assuming $25 \%$ embryonic lethality for Pcsk6 tm1Rob mice: 27:55:18\% $\left(\right.$ Pcsk6 $^{+/+}:$Pcsk6 $^{\text {tm1Rob/+ }}:$ Pcsk6 $\left.^{\text {tm1Rob }} ; n=267\right)$.

\section{Histological assessment of ovaries}

Ovaries were harvested, fixed for $24 \mathrm{~h}$ in $10 \%$ acetate-buffered formalin, and then embedded in paraffin. Ovaries were sectioned serially at $4 \mu \mathrm{m}$ and stained automatically with hematoxylin and eosin using a Thermo Shandon Gemini Stainer by the Centre for Modeling Human Disease (CMHD) Pathology Core at The Toronto Centre for Phenogenomics (Toronto, ON, Canada). All stained serial sections were assessed by a minimum of two independent observers in the Nachtigal laboratory, and by Dr Susan Newbigging, a veterinary pathologist and Director of Pathology at the CMHD Pathology Core. Observers were blinded to the genotype and age of the samples. Definitions of normal and pathological features are included as supplementary information 
(Supplementary Figure 3, see section on supplementary data given at the end of this article).

\section{Breeding analysis}

Wild-type Pcsk6 (Pcsk6 $\left.{ }^{+/+}\right)$and Pcsk6 $6^{\text {tm1Rob }}$ female mice were paired at 6 weeks of age with $P c s k 6^{+/+}$male mice. The number of litters and number of offspring were measured for 12 mo after pairing. The data discussed correspond to when the breeding female was 3-9 mo of age, the period of peak cyclicity for female mice (Nelson et al. 1982).

\section{Estrous cycle}

Virgin female mice were evaluated for estrous cyclicity by daily vaginal smears (taken between 0800 and $1100 \mathrm{~h}$ ) for a minimum of 4 weeks. Smears were obtained using a sterile saline-moistened cotton-tipped applicator. Slides were allowed to air dry and subsequently stained using DipQuick Stain kit (Jorgenson Laboratories, Inc., Loveland, CO, USA). Vaginal smears were examined and classified into one of seven estrous phases, as described by Nelson et al. (1982).

\section{Serum FSH, $L H$, and steroid measurements}

For serum FSH and $\mathrm{LH}$ measurements, virgin mice were evaluated over two consecutive cycles prior to harvesting. Mice displaying estrous cyclicity were harvested at $\sim 1700 \mathrm{~h}$ on the day of proestrous-estrous, and serum was obtained and stored at $-80{ }^{\circ} \mathrm{C}$ until analyzed. FSH and $\mathrm{LH}$ levels were determined by RIA through custom service from the National Hormone and Peptide Program (NHPP) through the US NIH National Institute of Diabetes and Digestive and Kidney Diseases (www.humc. edu/hormones/material.html). Each sample was examined in duplicate. Mouse FSH was detected using guinea pig antimouse FSH (AFP1760191) at a final dilution of 1:200 000 . Mouse LH was detected using NIDDK-anti-rat LH-S-11 at a final dilution of 1:1 500000 .

Serum concentrations of $17 \beta-E_{2}$, testosterone, and $P_{4}$ were measured by the Endocrine Technology and Support Core Lab at the Oregon National Primate Research Center (Rasmussen et al. 1984). Serum steroids were organically extracted, followed by column chromatography using Sephadex LH-20 for separation, and a specific RIA was used to measure each steroid. Hormonal values were corrected for extraction chromatography losses determined by radioactive trace recovery at the same time with sample extraction. The efficiency for steroid recovery was $77 \%$ for $E_{2}, 85 \%$ for testosterone, and $88 \%$ for $\mathrm{P}_{4}$. Assay sensitivity was $1 \mathrm{pg} /$ tube for the $E_{2}$ RIA, $2.5 \mathrm{pg} /$ tube for the testosterone RIA, and $5 \mathrm{pg} /$ tube for the $\mathrm{P}_{4}$ RIA. Intra-assay variation for the extraction chromatography RIA was estimated at $15.5 \%$ for $E_{2}, 18.7 \%$ for testosterone, and $16.9 \%$ for $\mathrm{P}_{4}$.

\section{Stimulation with eCG}

Female mice at ages 30-48 days were injected i.p. with saline or $10 \mathrm{IU}$ of eCG (NHPP). The age distribution was the same in WT and KO mice. Blood samples were collected, and ovaries harvested for total RNA extraction 48 or $60 \mathrm{~h}$ after eCG injection.

\section{Superovulation studies}

Immature 30-day-old (d) and 3-mo-old female mice were injected i.p. with $10 \mathrm{IU}$ of eCG (Folligon; Intervet, Kirkland, QC, Canada) and $48 \mathrm{~h}$ later with $10 \mathrm{IU}$ of human chorionic gonadotropin (Chorulon; Intervet). Mice were harvested $26 \mathrm{~h}$ after Chorulon injection, and the oocytes were isolated from the ampulla. The number of oocytes was determined by direct count.

\section{RNA isolation and QPCR}

Total RNA was isolated from mouse tissue using the GeneElute Total Mammalian RNA MiniPrep Kit (Sigma). From each mouse, one ovary was used to isolate RNA, and the other ovary was used for histological assessment. For QPCR experiments, cDNA was generated from $2 \mu \mathrm{g}$ of total RNA using Superscript III reverse transcriptase (Invitrogen). QPCR was performed using the Brilliant SYBR Green QPCR Master Mix and the Mx3000P Quantitative PCR machine and analysis software (Stratagene, La Jolla, CA, USA). RNA levels were assessed by QPCR (40 cycles: $30 \mathrm{~s}$ at $95{ }^{\circ} \mathrm{C}, 30 \mathrm{~s}$ at $59{ }^{\circ} \mathrm{C}, 30 \mathrm{~s}$ at $72{ }^{\circ} \mathrm{C}$ ) using primers specific for each mouse cDNA sequence (Supplementary Table 2, see section on supplementary data given at the end of this article for list of primers). Melting curves were performed on each reaction to confirm the specificity of the QPCR, and PCR amplicons were subcloned and verified by sequencing. Data were analyzed relative to mouse RNA polymerase II (mrpll) and expressed as relative fold change. Fold difference in RNA expression between $P c s k 6^{+/+}$ and Pcsk ${ }^{\text {tm1Rob }}$ mice was calculated using the normalized $C_{t}$

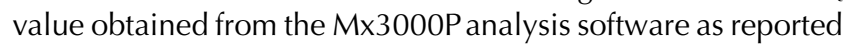
previously (Livak \& Schmittgen 2001); expression levels in basal samples from wild-type ovaries was set to 1 .

\section{Statistical analyses}

All data were analyzed for statistical significance using GraphPad Prism 4.0 software (GraphPad Software, Inc., San Diego, CA, USA). For FSH, LH, and calculation of whelping interval, data were analyzed using unpaired $t$-test with Welch's correction, not assuming equal variances. Differences were considered significant at $P \leq 0.05$. Serum FSH and LH measurements are expressed as the mean \pm S.E.M. An unpaired $t$-test was performed for experiments examining serum steroids, gene expression, and ovulatory capacity in response to exogenous hormonal stimulation where significance was set at $P \leq 0.05$.

\section{Supplementary data}

This is linked to the online version of the paper at http://dx.doi. org/10.1530/REP-10-0451. 


\section{Declaration of interest}

The authors declare that there is no conflict of interest that could be perceived as prejudicing the impartiality of the research reported.

\section{Funding}

This study was supported equally by the Canadian Cancer Society from a grant administered by the National Cancer Institute of Canada (Grant \#16276), and by a Canadian Institute of Health Research regional partnership grant (Grant \# ROP91758) partnered with the Nova Scotia Health Research Foundation (Grant \# MED-Matching-2008-4881) and the Dalhousie Cancer Research Program. M W Nachtigal was supported as a Research Scientist of the Canadian Cancer Society through an award from the National Cancer Institute of Canada, and M L Mujoomdar was supported by the Rossetti Fellowship for Cancer Research administered by the Dalhousie Medical Research Foundation.

\section{Acknowledgements}

The authors wish to acknowledge Professor D Constam (Swiss Institute for Experimental Cancer Research) for providing the Pcsk6 ${ }^{\text {tm1Rob }}$ mice. We are especially grateful to Dr Susan Newbigging and Lily Morikawa at the CMHD Pathology Core for their exceptional contribution toward the assessment of the histopathology of the mouse ovaries. We thank Elizabeth Campbell and Stephanie Samson for their excellent technical assistance, and Professors Peter A Cattini and Mary Lynn Duckworth for their critical review of this manuscript.

\section{References}

Ahmed W, Orasanu G, Nehra V, Asatryan L, Rader DJ, Ziouzenkova O \& Plutzky J 2006 High-density lipoprotein hydrolysis by endothelial lipase activates PPARalpha: a candidate mechanism for high-density lipoprotein-mediated repression of leukocyte adhesion. Circulation Research 98 490-498. (doi:10.1161/01.RES.0000205846.46812.be)

Bassi DE, Fu J, Lopez de Cicco R \& Klein-Szanto AJ 2005 Proprotein convertases: "master switches" in the regulation of tumor growth and progression. Molecular Carcinogenesis 44 151-161. (doi:10.1002/mc. 20134)

Beck S, Le Good JA, Guzman M, Ben Haim N, Roy K, Beermann F \& Constam DB 2002 Extraembryonic proteases regulate nodal signalling during gastrulation. Nature Cell Biology 4 981-985. (doi:10.1038/ ncb890)

Broedl UC, Maugeais C, Marchadier D, Glick JM \& Rader DJ 2003 Effects of nonlipolytic ligand function of endothelial lipase on high density lipoprotein metabolism in vivo. Journal of Biological Chemistry 278 40688-40693. (doi:10.1074/jbc.M304367200)

Broedl UC, Jin W, Marchadier D, Secreto A \& Rader DJ 2005 Tissuespecific expression pattern of human endothelial lipase in transgenic mice. Atherosclerosis 181 271-274. (doi:10.1016/j.atherosclerosis. 2005.01.027)

Constam DB \& Robertson EJ 2000 SPC4/PACE4 regulates a TGFbeta signaling network during axis formation. Genes and Development $\mathbf{1 4}$ 1146-1155.

Conway GS 2000 Premature ovarian failure. British Medical Bulletin 56 643-649.
Diaz FJ, Sugiura K \& Eppig JJ 2008 Regulation of Pcsk6 expression during the preantral to antral follicle transition in mice: opposing roles of FSH and oocytes. Biology of Reproduction 78 176-183. (doi:10.1095/ biolreprod.107.063537)

Freyer C, Kilpatrick LM, Salamonsen LA \& Nie G 2007 Pro-protein convertases (PCs) other than PC6 are not tightly regulated for implantation in the human endometrium. Reproduction 133 1189-1197. (doi:10.1530/REP-06-0285)

Froment P, Gizard F, Defever D, Staels B, Dupont J \& Monget P 2006 Peroxisome proliferator-activated receptors in reproductive tissues: from gametogenesis to parturition. Journal of Endocrinology 189 199-209. (doi:10.1677/joe.1.06667)

Fu Y, Campbell EJ, Shepherd TG \& Nachtigal MW 2003 Epigenetic regulation of proprotein convertase PACE4 gene expression in human ovarian cancer cells. Molecular Cancer Research 1 569-576.

Fuki IV, Blanchard N, Jin W, Marchadier DH, Millar JS, Glick JM \& Rader DJ 2003 Endogenously produced endothelial lipase enhances binding and cellular processing of plasma lipoproteins via heparan sulfate proteoglycan-mediated pathway. Journal of Biological Chemistry 278 34331-34338. (doi:10.1074/jbc.M302181200)

Gauster M, Hrzenjak A, Schick K \& Frank S 2005 Endothelial lipase is inactivated upon cleavage by the members of the proprotein convertase family. Journal of Lipid Research 46 977-987. (doi:10.1194/jlr. M400500-JLR200)

Iatan I, Dastani Z, Do R, Weissglas-Volkov D, Ruel I, Lee JC, HuertasVazquez A, Taskinen MR, Prat A, Seidah NG et al. 2009 Genetic variation at the proprotein convertase subtilisin/kexin type 5 gene modulates high-density lipoprotein cholesterol levels. Circulation. Cardiovascular Genetics 2 467-475. (doi:10.1161/CIRCGENETICS. 109.877811)

Ishida T, Choi S, Kundu RK, Hirata K, Rubin EM, Cooper AD \& Quertermous T 2003 Endothelial lipase is a major determinant of HDL level. Journal of Clinical Investigation 111 347-355. (doi:10.1172/ JCI16306)

Ishimura K, Matsuda H, Tatsumi H, Fujita $H$, Terada N \& Kitamura $Y$ 1986 Ultrastructural changes in the ovaries of SI/Slt mutant mice, showing developmental deficiency of follicles and tubular adenomas. Archivum Histologicum Japonicum. Nippon Soshikigaku Kiroku 49 379-389.

Jin W, Fuki IV, Seidah NG, Benjannet S, Glick JM \& Rader DJ 2005 Proprotein convertases [corrected] are responsible for proteolysis and inactivation of endothelial lipase. Journal of Biological Chemistry $\mathbf{2 8 0}$ 36551-36559. (doi:10.1074/jbc.M502264200)

Johnson RC, Darlington DN, Hand TA, Bloomquist BT \& Mains RE 1994 PACE4: a subtilisin-like endoprotease prevalent in the anterior pituitary and regulated by thyroid status. Endocrinology 135 1178-1185. (doi:10. 1210/en.135.3.1178)

Kawano Y \& Kypta R 2003 Secreted antagonists of the Wnt signalling pathway. Journal of Cell Science 116 2627-2634. (doi:10.1242/jcs.00623)

Kiefer MC, Tucker JE, Joh R, Landsberg KE, Saltman D \& Barr PJ 1991 Identification of a second human subtilisin-like protease gene in the fes/fps region of chromosome 15. DNA and Cell Biology 10 757-769. (doi:10.1089/dna.1991.10.757)

Kumar TR, Palapattu G, Wang P, Woodruff TK, Boime I, Byrne MC \& Matzuk MM 1999 Transgenic models to study gonadotropin function: the role of follicle-stimulating hormone in gonadal growth and tumorigenesis. Molecular Endocrinology 13 851-865. (doi:10.1210/me.13.6.851)

Levallet J, Koskimies P, Rahman N \& Huhtaniemi I 2001 The promoter of murine follicle-stimulating hormone receptor: functional characterization and regulation by transcription factor steroidogenic factor 1 . Molecular Endocrinology 15 80-92. (doi:10.1210/me.15.1.80)

Li M, Mbikay M \& Arimura A 2000 Pituitary adenylate cyclase-activating polypeptide precursor is processed solely by prohormone convertase 4 in the gonads. Endocrinology 141 3723-3730. (doi:10.1210/en.141.10. 3723)

Lindegaard ML, Nielsen JE, Hannibal J \& Nielsen LB 2005 Expression of the endothelial lipase gene in murine embryos and reproductive organs. Journal of Lipid Research 46 439-444. (doi:10.1194/jlr.M400417JLR200)

Livak KJ \& Schmittgen TD 2001 Analysis of relative gene expression data using real-time quantitative PCR and the $2(-$ Delta Delta $C(\mathrm{~T}))$ method. Methods 25 402-408. (doi:10.1006/meth.2001.1262) 
Ma K, Cilingiroglu M, Otvos JD, Ballantyne CM, Marian AJ \& Chan L 2003 Endothelial lipase is a major genetic determinant for high-density lipoprotein concentration, structure, and metabolism. PNAS $\mathbf{1 0 0}$ 2748-2753. (doi:10.1073/pnas.0438039100)

Matzuk MM \& Lamb DJ 2002 Genetic dissection of mammalian fertility pathways. Nature Medicine 8 (Suppl) S33-S40. (doi:10.1038/ncb-nmfertilitys41)

Maxwell KN \& Breslow JL 2005 Proprotein convertase subtilisin kexin 9: the third locus implicated in autosomal dominant hypercholesterolemia. Current Opinion in Lipidology 16 167-172. (doi:10.1097/01.mol. 0000162321.31925.a3)

Mbikay M, Seidah NG, Chretien M \& Simpson EM 1995 Chromosomal assignment of the genes for proprotein convertases PC4, PC5, and PACE 4 in mouse and human. Genomics 26 123-129. (doi:10.1016/08887543(95)80090-9)

Murphy ED 1972 Hyperplastic and early neoplastic changes in the ovaries of mice after genic deletion of germ cells. Journal of the National Cancer Institute 48 1283-1295.

Murphy ED \& Beamer WG 1973 Plasma gonadotropin levels during early stages of ovarian tumorigenesis in mice of the $\mathrm{W} \times \mathrm{W}$ u genotype. Cancer Research 33 721-723.

Nelson JF, Felicio LS, Randall PK, Sims C \& Finch CE 1982 A longitudinal study of estrous cyclicity in aging C57BL/6J mice: I. cycle frequency, length and vaginal cytology. Biology of Reproduction 27 327-339. (doi:10.1095/biolreprod27.2.327)

Nour N, Mayer G, Mort JS, Salvas A, Mbikay M, Morrison CJ, Overall CM \& Seidah NG 2005 The cysteine-rich domain of the secreted proprotein convertases PC5A and PACE4 functions as a cell surface anchor and interacts with tissue inhibitors of metalloproteinases. Molecular Biology of the Cell 16 5215-5226. (doi:10.1091/mbc.E05-06-0504)

Page RE, Klein-Szanto AJ, Litwin S, Nicolas E, Al-Jumaily R, Alexander P, Godwin AK, Ross EA, Schilder RJ \& Bassi DE 2007 Increased expression of the pro-protein convertase furin predicts decreased survival in ovarian cancer. Cellular Oncology 29 289-299.

Rakhshandehroo M, Sanderson LM, Matilainen M, Stienstra R, Carlberg C, de Groot PJ, Muller M \& Kersten S 2007 Comprehensive analysis of PPARalpha-dependent regulation of hepatic lipid metabolism by expression profiling. PPAR Research 2007 26839. (doi:10.1155/2007/ 26839)

Rasmussen LE, Buss IO, Hess DL \& Schmidt MJ 1984 Testosterone and dihydrotestosterone concentrations in elephant serum and temporal gland secretions. Biology of Reproduction 30 352-362. (doi:10.1095/ biolreprod30.2.352)
Roebroek AJ, Umans L, Pauli IG, Robertson EJ, van Leuven F, Van de Ven WJ \& Constam DB 1998 Failure of ventral closure and axial rotation in embryos lacking the proprotein convertase furin. Development $\mathbf{1 2 5}$ 4863-4876.

Seidah NG \& Chretien M 1999 Proprotein and prohormone convertases: a family of subtilases generating diverse bioactive polypeptides. Brain Research 848 45-62. (doi:10.1016/S0006-8993(99)01909-5)

Seidah NG, Khatib AM \& Prat A 2006 The proprotein convertases and their implication in sterol and/or lipid metabolism. Biological Chemistry 387 871-877. (doi:10.1515/BC.2006.110)

St Germain C, Croissandeau G, Mayne J, Baltz JM, Chretien M \& Mbikay M 2005 Expression and transient nuclear translocation of proprotein convertase 1 (PC1) during mouse preimplantation embryonic development. Molecular Reproduction and Development 72 483-493. (doi:10. 1002/mrd.20271)

Tadros H, Chretien M \& Mbikay M 2001 The testicular germ-cell protease PC4 is also expressed in macrophage-like cells of the ovary. Journal of Reproductive Immunology 49 133-152. (doi:10.1016/ S0165-0378(00)00085-1)

Taylor NA, Van De Ven WJ \& Creemers JW 2003 Curbing activation: proprotein convertases in homeostasis and pathology. FASEB Journal 17 1215-1227. (doi:10.1096/fj.02-0831 rev)

Tsuji A, Sakurai K, Kiyokage E, Yamazaki T, Koide S, Toida K, Ishimura K \& Matsuda Y 2003 Secretory proprotein convertases PACE4 and PC6A are heparin-binding proteins which are localized in the extracellular matrix. Potential role of PACE4 in the activation of proproteins in the extracellular matrix. Biochimica et Biophysica Acta 1645 95-104. (doi:10.1016/S1570-9639(02)00532-0)

Vanderhyden BC 2005 Loss of ovarian function and the risk of ovarian cancer. Cell and Tissue Research 322 117-124. (doi:10.1007/s00441005-1100-1)

Vanderhyden BC, Shaw TJ \& Ethier JF 2003 Animal models of ovarian cancer. Reproductive Biology and Endocrinology 1 67. (doi:10.1186/ 1477-7827-1-67)

Wang H, Jiang JY, Zhu C, Peng C \& Tsang BK 2006 Role and regulation of nodal/activin receptor-like kinase 7 signaling pathway in the control of ovarian follicular atresia. Molecular Endocrinology 20 2469-2482. (doi:10.1210/me.2005-0446)

Received 9 November 2010

First decision 9 December 2010

Accepted 23 December 2010 